\title{
ESTIMATION OF BULL LIVE WEIGHT USING THERMAL IMAGING
}

\author{
STAJNKO, D.; Vindis, P. \& BERK, P.
}

Abstract: Estimating the live weight of cattle by measurement of body dimensions with thermography and thermal image analysis was studied during weighing of the Simmental breed. The experimental group of cattle was measured seven times every 60 days from housing at the average age of 135 days to slaughtering at 450 day. Each cattle was weighed, manually measured and captured by the thermal camera. This device, together with the image analysis algorithm, proved to be a successful tool for estimating the wither height (Wh) and hip height (Hh) during all seven age classes. A statistically significant relationship $(P<0.05)$ was found for all seven age classes, whereby the $R 2$ adj was varying with the age from 0.11 to 0.66 (BW1) and from 0.15 to 0.74 (BW2). Therefore the thermal camera shows to be a useful tool in estimating live $B W$, which is of significant importance in reducing stress during cattle growing.

Key words: thermography, image analysis, bull, body dimensions, weight
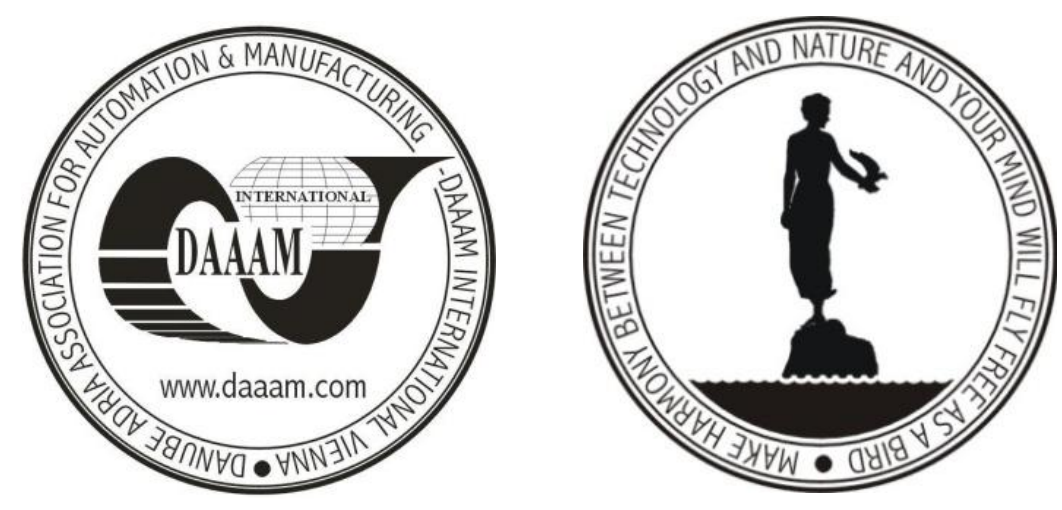

Authors' data: Assoc. Prof. Stajnko, D[enis], Bs. Agric. Eng. Vindis, P[eter], Bs. Electro. Eng. Berk, P[eter], University of Maribor, Faculty of Agriculture and Life Sciences, Vrbanska 30, SI-2000, Maribor, Slovenia, denis.stajnko@uni-mb.si, peter.vindis@uni-mb.si, peter.berk@uni-mb.si

This Publication has to be referred as: Stajnko, D[enis]; Vindis, P[eter] \& Berk, P[eter] (2010). Estimation of Bull Live Weight Using Thermal Imaging, Chapter 23 in DAAAM International Scientific Book 2010, pp. 227-236, B. Katalinic (Ed.), Published by DAAAM International, ISBN 978-3-901509-74-2, ISSN 1726-9687, Vienna, Austria

DOI: $10.2507 /$ daaam.scibook.2010.23 
Stajnko, D.; Vindis, P. \& Berk, P.: Estimation of Bull Live Weight Using Thermal ...

\section{Introduction}

The body mass is one of highly important indicators of the development of the young animal, therefore it is very essential to follow it up. Accurate data on the body mass are obtained by weighing with the use of various weighing devices, such as the spring ordinary weighing devices or more modern electronic weighing devices. Since the animals cannot be often weighed, the individual body parts are measured alternatively. Usually, measuring of the whither size suffices. However, as much as the calves deviate from the optimal body development, the establishing of the body mass deviates. In order to calculate the body mass more accurately, it is necessary to consider also the trunk length in addition to the whither size.

The body frame, size and length are in positive relation to intensity and capacity of meat production. Only the animals with sufficient body frame and with well muscled top - quality body parts can be successfully fattened to high body mass. With frequent establishing of the body mass the raisers can follow up the development of the animals, particularly the growth of young animals. The most reliable information about the body mass of cattle can be obtained by weighing of animals. However, the raisers do not have always available weighing devices. For this reason, they can resort to approximate establishing of the body mass on the basis of the animal's whither and hip size. However, the information acquired is less accurate than the one obtained by weighing. The differences are affected by the breed type, satiety of the animal, manner of feeding and even tightness of the tape during measuring (Kogel \& Utz, 1988, Janzekovic, et al.,2005).

The whither size as a basis for the determination of the body mass of living cattle is increased close behind the shoulder-bones. During this measuring the animal must stand with the legs placed parallel and the head should be kept normally (Fig. 1). Each time after the measurement is taken, the body mass is read according to the table. However, it must be kept into account that the determination of the body mass on the basis of the chest size is only approximate.

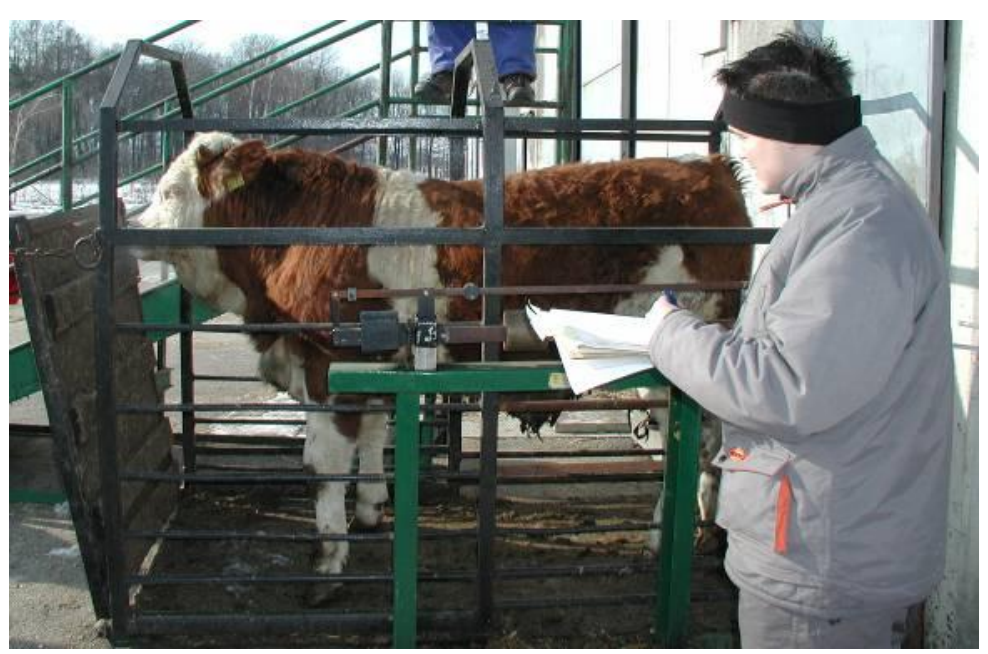

Fig.1. Common weighing of cattle on the scale

So far, automatic electronic weighing systems in combination with automatic identification equipment, and indirect weight determination from the dimension of 
the bull, either measured by tape, callipers or an image analysis system have been researched to find an alternative to the manual weighing procedure. These methods will be discussed in the following paragraphs.

\section{Automatic weighing}

Automatic weighting systems have been intensively researched for pigs, sheep and poultry, however in cattle production only weighting of dairy cows is reported by several authors. From many different models, two of them might be suggested for monitoring of young cattle.

Cveticanin \& Wendl (2004) designed the fuzzy-logic dynamic weighting system of dairy cow based on the mathematical model for simulating cow walk, which calculates the body weight with the absolute average error less than $2 \%$. The simplified two legged system measures the force to the ground when the animal is crossing the scale and generate a curve, which is compared with the database. Pastell et al. (2006) described another automatic weighing system made from four strain gauge balances equipment installed into a milking robot. The computer program was able to measure the average weight, the weight variation of each leg and total weight with $90 \%$ accuracy.

Since weighting of older cattle represents a dangerous job for the stableman, the significant correlation between live weight and dimensions of the cattle has led many authors to study the possibility of estimating body weight from the dimensions of the cattle. Heinrichs et al. (1992) indicated that the linear regression of body weight on heart girth had the highest $\mathrm{R}^{2}$, followed by hip width, body length and wither height. Although all measurements are highly correlated, addition of the second body measure contributes a little predictive benefit in the estimation of Holstein heifers' body weight. Also Wilson et al. (1997) detected the addition of heart girth as a second measurement to the wither height as the most important contribution for estimating the body weight of Holstein veal calves.

Enevoldsen \& Kristensen (1997) evaluated the use of wither height, hip height and width to predict the body weight. Seven regression models were developed based on indicators, which are relatively simple to obtain precisely because the anatomical locations are easy to identify.

Willeke \& Dürsch (2002) detected high significant correlation in hip height, heart girth and weight also for the Simmental heifers suggested the third order polynom equation as the most fitting.

\section{Determining of body dimensions}

In order to apply image analysis for weighting of animals, the determination of cattle body dimensions from images must be possible. Prior using the image processing a prediction function should be established using the relationship between body dimensions from acquired images and the live weight of the specific cattle breed. Since the image is only the $2 \mathrm{D}$ plain projection of the animal, the loss of one dimension limits the application of such system on measuring vertical and horizontal 
Stajnko, D.; Vindis, P. \& Berk, P.: Estimation of Bull Live Weight Using Thermal ...

dimensions. Therefore the prediction functions should be precise enough to obtain valid information and can be similar to those described in the previous chapter only whenever the hip height and wither height are included into polynomial equations. However, only a few references have been reported in weighting of the live young cattle.

Data were collected from May 2006 to June 2008 at the Faculty's experimental farm in Rogoza, which is licensed for processing a progeny test on approximately 400 Simmental cattle yearly. Two pens of 12 cattle were selected from the herd for the experiment. According to the progeny test requirements each calf was purchased from local farmers and was first weighted and measured at the housing. Then every two months the wither height, hip height and body mass of each cattle were measured until the slaughtering.

The examined cattle were captured from the side by the AGEMA 570 (Flir Systems ${ }^{\mathrm{TM}}$ ) thermal camera with an image resolution of $320 \times 240$ pixels. The emissivity of the object was set to 0.98 and the temperature resolution was better than $0.5^{\circ} \mathrm{C}$, which enables precise detection of body heat in any environmental condition. The measurements were performed using cold concrete wall surroundings, which enabled a temperature difference and therefore a sharp edge between the animal and the background on the capture images.

The uncertainty of body edge measurements depends on the image resolution and the position of animal in relation to the camera. Therefore, for holding the distance between the camera and the object constant for all measurements, the animals were guided through a narrow corridor, which also prevented the animal from moving perpendicular to the camera. When the animal was walking though the corridor, we were waiting until it stood in an appropriate position on the image frame. Such procedure was possible because the animals were not aware of being captured by the thermal camera.
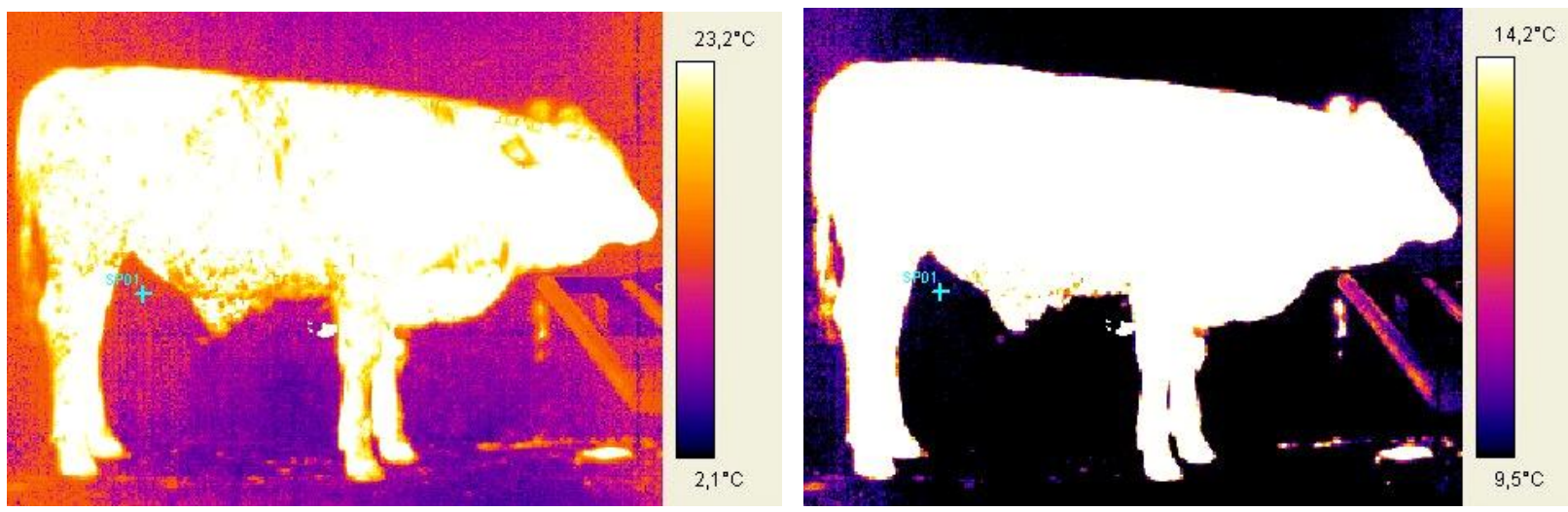

Fig. 2. Sample thermal images at $320 \times 240$ pixel resolution showing a $280 \mathrm{~kg}$ cattle before (left) and after temperature adjustment (right)

Since a thermal camera supports only its own IMG image format, each series of images was first converted into a BMP format prior to further image processing. As seen from Fig. 2, during this process, contrasts between the cattle body and the 
background was extended by adjusting the temperature scale on each series of thermal images according to the average body and surroundings temperature.

In the following paragraphs the algorithm for determination of animal's measures will be illustrated with one sample of a cattle image (Fig. 3), chosen to be representative for demonstrating the results of the procedure. As seen from the BMP image, the thermal camera was able to separate the cattle from the surroundings accurately, so any additional image separation was not required. Prior to every set of measurements a Lidtin's stick was captured on the image together with the animal. It was applied for the pixel/unit calibration as it ensured enough temperature gradient to the cattle body, which was required for the automatic image processing. Because the thermal image was relatively small for precise measurements, all calculations were conducted on the sub pixel level, which increased the accuracy significantly.

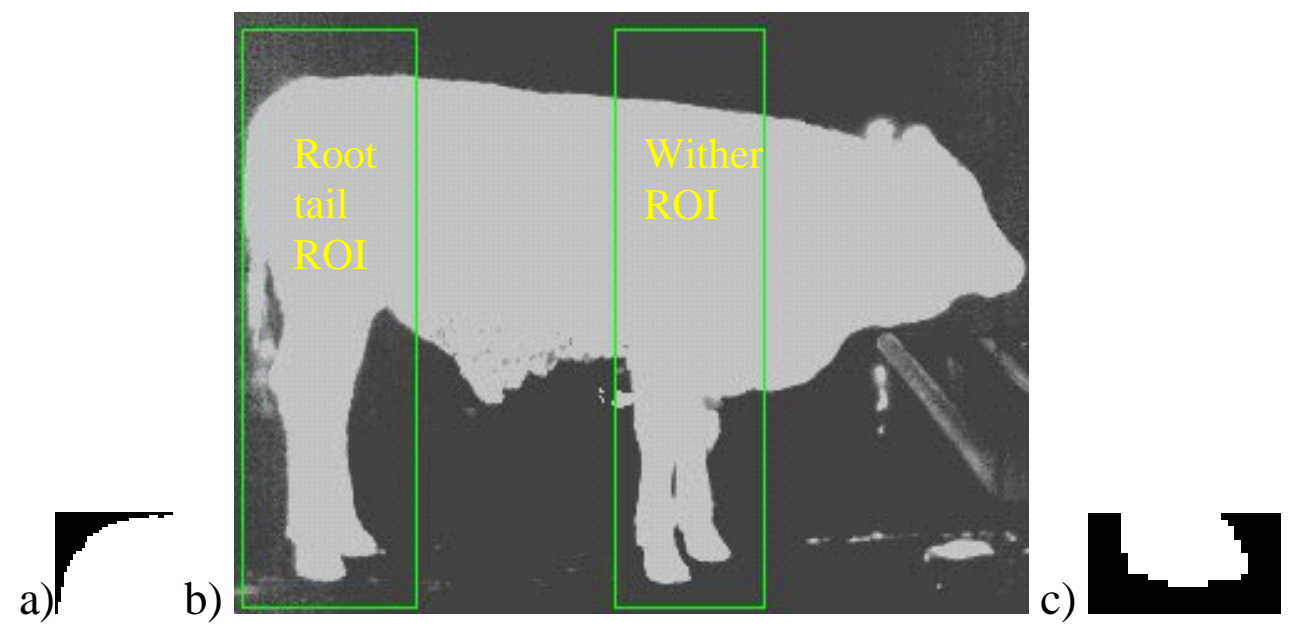

Fig. 3. Root tail mask (a) and front hoof mask (c) for locating a starting point of the coordinate system on each of two ROIs (green line) on the 8-bit image (b)

\section{Image analysis procedure}

\subsection{ROIs and templates}

The measurements were based on the idea of fixing the root tail (Fig. 3a) and front hoof templates (Fig. 3c) on each image and adjusting the coordinate system accordingly, so that different positions of the animal did not influence the measurements. To prevent finding incorrect positions, procedure for locating the root tail was limited to the root tail ROI and procedure for determining the front roof to the wither ROI, respectively.

As shown on the Fig. 3, a root tail ROI and a wither ROI image were defined uniformly on the each image, which served for locating the initial points for measuring wither and root. Firstly, a mask image containing the sample of root tail was applied on the root tail ROI in the first stage. Once the root tail was located on the ROI, the new coordinate system was fixed to animal root tail (Fig. 4b), whereby the bottom left corner of the root tail template was given the coordinates $(0.0)$. Similar procedure was also applied for locating of front hoof mask (Fig. 3c) on the wither ROI (Fig. 4d). 
Stajnko, D.; Vindis, P. \& Berk, P.: Estimation of Bull Live Weight Using Thermal ...

\subsection{Locate hip procedure}

Before determining the hip height $(H h)$, the hip (HipY) had to be found on the boundary, whereby the HipY was assumed as a small saddle point on the boundary. Therefore for describing and locating it a polynomial mathematical model was developed, which fit the boundary quite well. However, by calculating the first derivate of $Y$ points not one extreme was detected, thus for the selection of saddle points the following relational and logical operations were additionally carried out:

$$
\text { HipY } \ldots . . \mathrm{y}_{(\mathrm{i})}^{\prime}=0 \text { and } y^{\prime \prime}{ }_{(i-1)}>0 \text { and } y^{\prime \prime}{ }_{(i+1)}<0
$$
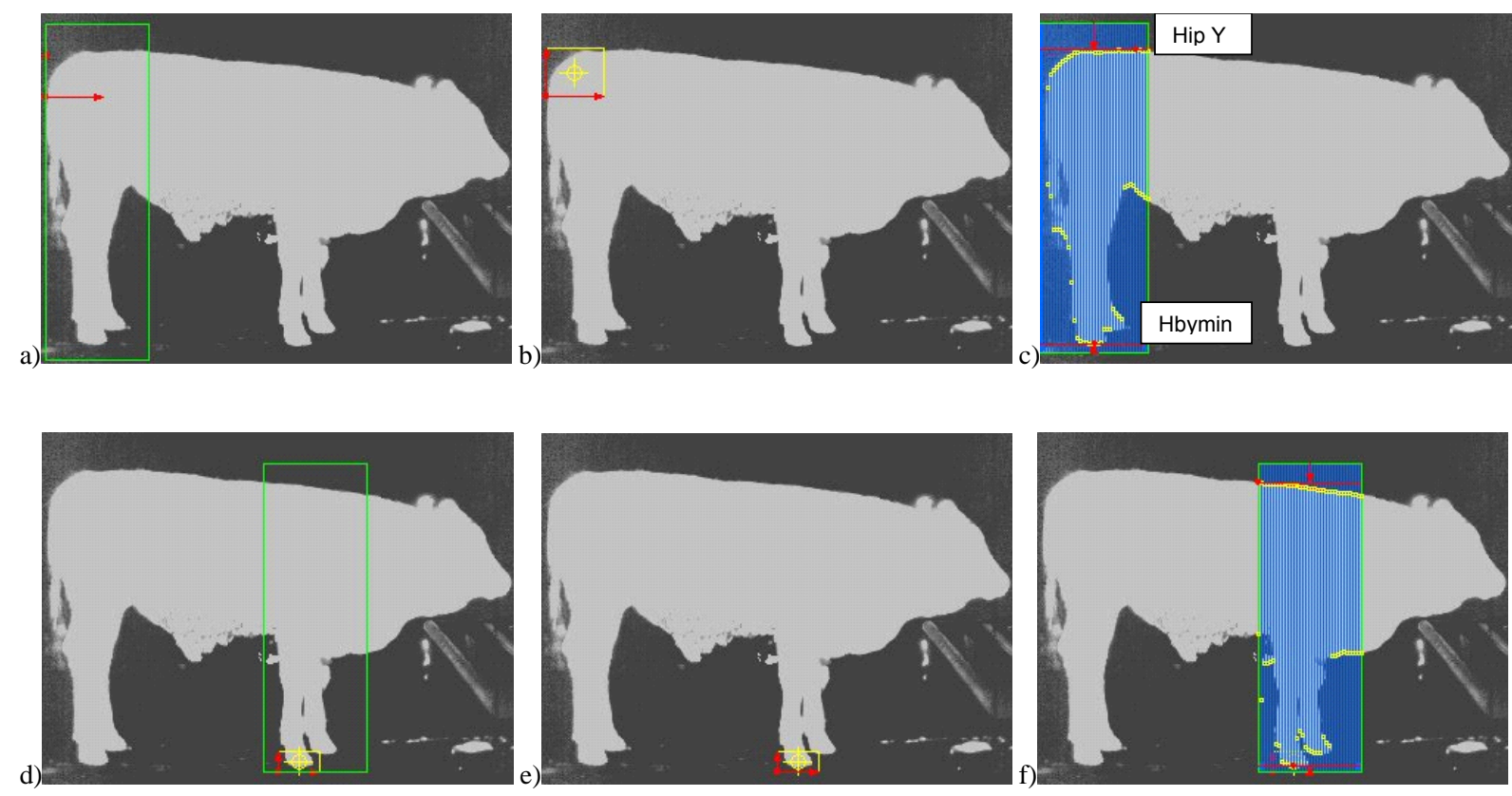

Fig. 4. Image processing to obtain the body dimensions; a) root tail ROI, b) fixing new root coordinate, c) hip height measurement, d) wither ROI, e) fixing front hoof coordinates, f)wither height measurement.

\subsection{Procedure for measuring hip}

As seen from the Fig. 4c, the hip height $(H h)$ was defined as the longest vertical distance between the HipY and the bottom part of the back hoof $\left(H b y_{\min }\right)$, which had to be located from the root tail ROI.

\subsection{Locate wither procedure}

Before determination of the wither height $(W h)$, the wither point (WitY) was found on the upper part of the boundary layer first. A wither was assumed to be a local maximum point inside the wither ROI. Therefore another polynomial mathematical model was developed, which fit the real wither accurately. After processing the first derivate of $Y$ points on such model, the minimum extreme points were calculated (yellow line) and compared to measured data according to the following relational and logical operations:

$$
W y_{\max } \ldots . . \mathrm{y}_{(\mathrm{i})}^{\prime}=0 \text { and } y_{(i-1)}<\mathrm{y}_{(\mathrm{i})}<\mathrm{y}_{(i+1)}
$$




\subsection{Measure wither}

A wither was defined as the longest vertical distance between wither (WitY)and the most bottom part of the front hoof $\left(H f y_{\text {min }}\right)$ on the boundary layer. As seen from the Fig. 4f, this point was assumed to be the most bottom point of the wither ROI.

\subsection{Calculating weight}

As already reported by Enevoldsen \& Kristensen (1997) and Heinrichs et al. (1992) the wither height and the hip height was determined as most significant body dimensions for estimating the cattle body weight; therefore, also in our research experiment three similar regression models were chosen to be investigated:

$$
\begin{array}{ll}
(B W 1) B w=-1072.47+12.47 * W h & R^{2}=0.89(p<0.01) \\
(B W 2) B w=-1277.40+13.50 * R h & R^{2}=0.93(p<0.01) \\
(B W 3) B w=-1236.50+3.01 * W h+10.301 * R h \quad R^{2}=0.93(p<0.01)
\end{array}
$$

On the basis of the eight-year data set, the above three models for calculating the cattle weight were developed, which include main body characteristics of each animal of the given Simmental herd. Since, in the period of progeny test all cattle were in fact sons of eight cattle sire lines, the herd was genetically relative unique. Thus, the applied models served excellently for evaluating our group of experimental animals.

Various commercial programs for performing the above described procedure exist. In our research the IMAQ Vision 6.1.1. and Labview 7.0. from National Instruments ${ }^{\circledR}$ were used for processing all algorithms. Statistical analyses of results obtained by manual measurements and by thermal imaging were performed by using a SPSS Package Program 13.0.

\section{Results}

A Table 1 represents the summary statistics for means, standard deviations and coefficient of variation for whither height and hip height of the experimental Simmental cattle at different age of animals. In the Table 2 the mean cattle weight estimation is represented on the basis of three regression models BW 1, BW 2 and BW3, respectively which clearly show that the body weight of animals was better predicted with all models from the middle period of testing than at the first two measurements.

Also Wilson et al. (1992) reported better results for week 16 than week 8 and 4, whenever testing the Holstein veal calves for the period of 14 weeks. Thus, it was suggested for the future experiments to take BW 3 model with the wither height and hip height input parameters as most accurate for estimating weight of young cattle at the average age of 139 days.

At the second weighting (day 207) all three models overestimated the body weight above all other periods, which was probably due to the different body shapes. However, the BW 1 model fit the measured datamost closely. 
Stajnko, D.; Vindis, P. \& Berk, P.: Estimation of Bull Live Weight Using Thermal ...

For all successive weightings the body weight was estimated similarly with all models. Contrary, for the last measurement at day 449, the SD for BW 1 was slightly higher than for the BW 2 and BW 3. Although the BW 1 resulted in the smallest absolute difference from the weighted body weight again, it is clearly seen from the SD values (Table 2) that additional body dimensions need to be introduced into upcoming models for this particular age of animals.

\begin{tabular}{|c|c|c|c|c|c|c|c|c|c|c|c|c|}
\hline AGE & \multicolumn{3}{|c|}{$\mathrm{Wh}_{\mathrm{m}}$} & \multicolumn{3}{c|}{$\mathrm{Wh}_{\mathrm{e}}$} & \multicolumn{3}{c|}{$\mathrm{Hh}_{\mathrm{m}}$} & \multicolumn{3}{c|}{$\mathrm{Hh}_{\mathrm{t}}$} \\
\hline (days) & $\bar{x}$ & $\mathrm{SD}$ & $\mathrm{CV}$ & $\bar{x}$ & $\mathrm{SD}$ & $\mathrm{CV}$ & $\bar{x}$ & $\mathrm{SD}$ & $\mathrm{CV}$ & $\bar{x}$ & $\mathrm{SD}$ & $\mathrm{CV}$ \\
\hline 139 & 102 & 3.54 & 3.47 & 102 & 5.81 & 5.70 & 109 & 3.21 & 2.94 & 109 & 6.04 & 5.54 \\
\hline 207 & 107 & 4.83 & 4.51 & 112 & 4.12 & 3.68 & 115 & 3.57 & 3.10 & 120 & 2.74 & 2.28 \\
\hline 261 & 116 & 3.23 & 2.78 & 120 & 3.73 & 3.11 & 122 & 3.22 & 2.64 & 126 & 3.28 & 2.60 \\
\hline 317 & 122 & 2.92 & 2.39 & 125 & 3.91 & 3.13 & 129 & 2.3 & 1.78 & 129 & 3.09 & 2.40 \\
\hline 380 & 129 & 3.19 & 2.47 & 128 & 3.12 & 2.44 & 133 & 3.06 & 2.30 & 134 & 2.92 & 2.18 \\
\hline 401 & 128 & 4.01 & 3.13 & 130 & 2.45 & 1.88 & 135 & 3.71 & 2.75 & 135 & 2.34 & 1.73 \\
\hline 449 & 133 & 3.27 & 2.46 & 132 & 1.92 & 1.45 & 138 & 3.21 & 2.33 & 137 & 1.50 & 1.09 \\
\hline $\mathrm{R}^{2}$ & \multicolumn{9}{|c|}{$0.7479^{* *}$} \\
\hline
\end{tabular}

$\ldots \mathrm{p}<0.01, \mathrm{Wh}_{\mathrm{m}}$ wither height manually, $\mathrm{Wh}_{\mathrm{e}}$ wither height estimated, $\mathrm{Hh}_{\mathrm{m}}$ hip height manually, $\mathrm{Hh}_{\mathrm{e}}$ hip height estimated Tab. 1. Mean wither height (Wh) and hip height (Hh) of Simmental cattle measured manually and estimated with thermal camera at different ages $(n=24)$

Our correlation coefficients for estimating the body weight on the basis of developed three models are very close to results of Enevoldsen \& Kristensen (1997) on Danish Frisien and Jersey cows, whereby the established $\mathrm{R}^{2}$ varied between 0,80 and 0,89 . Moreover, the results of our linear regression models correspond very well with the linear models developed by Wilson et al. (1997) for measuring the body weight of special-fed Holstein veal calves, the established $\mathrm{R}^{2}$ was 0,73 for the wither height and 0,89 for the hip height, respectively. Knowing that several hundred animals were manually measured in both foreign experiments, our experiments with the thermography followed by image analysis procedure is feasible and equivalent method for predicting the body weight on live animals.

Furthermore, when comparing the results of our experiment with Heinrichs et al. (1992), who on a much bigger sample of experimental heifers, undoubtedly established better correlations for hip height $\left(R^{2}=0.95\right)$, for wither height $\left(R^{2}=0.94\right)$ and for both dimensions together $\left(\mathrm{R}^{2}=0.98\right)$. However, our procedure for indirect estimating of body weight from images represents already at the current point of development an accurate procedure, which have to be evaluated also in other breeds and fodder conditions. 
The high correlation between the measured and estimated body weight of young cattle indicates that all three models applied our research estimated the cattle weight accurately during the whole observing period, although a little difference between all models appeared at a particular age of cattle development.

\begin{tabular}{|c|c|c|c|c|c|c|c|c|c|c|c|}
\hline AGE & \multicolumn{1}{|c|}{ BWm (kg) } & \multicolumn{2}{|c|}{ BW 1 (kg) } & \multicolumn{3}{|c|}{ BW 2 (kg) } & \multicolumn{3}{|c|}{ BW 3 (kg) } \\
\hline \multirow{2}{*}{ days } & $\bar{x}$ & SD & $\bar{x}$ & SD & $\begin{array}{c}\text { BW1/ } \\
\text { BWm }\end{array}$ & $\bar{x}$ & SD & $\begin{array}{c}\text { Index } \\
\text { BW2/ } \\
\text { BWm }\end{array}$ & $\bar{x}$ & SD & $\begin{array}{c}\text { BWdex } \\
\text { BW/ } \\
\end{array}$ \\
\hline 139 & 181 & 31,19 & 193 & 72,42 & 110 & 190 & 81,58 & 105 & 189 & 79,48 & 104 \\
\hline 207 & 254 & 38,78 & 318 & 51,27 & 125 & 346 & 37,01 & 136 & 339 & 39,56 & 133 \\
\hline 261 & 356 & 46,98 & 420 & 46,53 & 118 & 424 & 44,27 & 119 & 423 & 44,27 & 119 \\
\hline 317 & 450 & 35,9 & 481 & 48,66 & 107 & 470 & 41,68 & 104 & 473 & 42,76 & 105 \\
\hline 380 & 498 & 26,68 & 522 & 38,91 & 105 & 527 & 39,37 & 106 & 527 & 39,28 & 106 \\
\hline 401 & 528 & 51,15 & 551 & 30,57 & 104 & 550 & 31,54 & 104 & 551 & 30,93 & 104 \\
\hline 449 & 594 & 30,29 & 573 & 23,94 & 96 & 568 & 20,27 & 96 & 570 & 20,75 & 96 \\
\hline $\mathrm{R}^{2}$ & & & & 0,796 & & & $0,792^{* *}$ & & & $0,798^{* *}$ \\
\hline
\end{tabular}

$\ldots \mathrm{p}<0,01$

BWm body weight manually

BW 1 estimated body weight with model 1

BW 2 estimated body weight with model 2

BW 3 estimated body weight with model 3

Tab. 2. Mean body weight of experimental Simmental cattle measured manually and estimated with three models at different ages $(n=24)$

The thermal camera and image analysis system was proved to enable faster and more frequent investigation of cattle body weight even in the growing pens without painful stress for the whole herd then common weighing on the electronic device. However, for wider on-line application in the open field, the introduction of the simplest BW 1 model with the measuring of hip height is preferred, since the measuring of wither height (BW 2 model) requires better positioning of the animal during capture with the camera, which is relatively difficult to achieve on the pasture. Measuring wither height was shown particularly difficult with young cattle until the average age of 340 days, which was very wild in the pens as well during weighing on scales.

\section{Acknowledgements}

This research was funded by The Ministry of Agriculture, Forestry and Food of the Republic of Slovenia, project number02-15-96/2006. The funding is gratefully acknowledged.The authors also acknowledge the vital contributions madeby the 
Stajnko, D.; Vindis, P. \& Berk, P.: Estimation of Bull Live Weight Using Thermal ... following colleagues: Marko Ocepek, who was responsiblefor the manual measurements, Petra Eker the head ofthe stable and stableman Aleš Pauman, who were always willingto help during the measurements on the scale.

\section{References}

Enevoldsen, C. \& Kristensen, T. (1997). Estimation of Body Weight from Body size measurements and body condition scores in dairy cows. Journal of Dairy Science,80(9),p. 1988-1995, ISSN 0022-0302, The American Dairy Science Association, USA

Heinrichs, A.J., Rogers, G.W. \& Copper, J.B. (1992). Predicting body weight and wither height in Holstein using body measurements. Journal of Dairy Science 75(12),p. 3546-3581, ISSN 0022-0302, The American Dairy Science Association, USA

Janzekovic, M., Mursec, B., Cus, F., Ploj, A., Janzekovic, I. \& Zuperl, U. (2005). Use of machines for liquid manure aerating and mixing, Journal of Materials Processing Technology 162-163, p. 744-750, ISSN 0924-0136, Elsevier, Nederland

Kmet, J., Sakowski, T., Huba, J., Peskovicova, D., Chrenek, J. \& Polak, P., (2000). Application of video image analysis in the slaughter value estimation of live Simmental bulls. Archiv für Tierzucht. 43, (4), p. 411-416, ISSN 0003-9438, Leibniz Institute for Farm Animal Biology, Dummerstorf, Germany

Kogel, S. \& Utz, J. (1988). Wie gut eigenen sich Fleckviehbullen fur Gebrauchskreuzungen. Tierzuchter 40, p. 385-388, ISSN, 0040-7364

Meuwissen, T.H.E. (1997). Maximizing the response of selection with a predefined rate of inbreeding. J. Anim. Sci. 75, p. 934-940, ISSN: 0021-8812, American Society of Animal Science, USA

Brandl, N. \& Jørgensen, E. (1996). Determination of live weight of pigs from dimensions measured using image analysis. Computers and electronics in agriculture. 15, p. 52-72, ISSN0168-1699, Elsevier, Nederland

Willeke, H., \& Dürsch, T. (2002). Prediction of the body weight of Simmental heifers using heart girth measurements. Archiv für Tierzucht, 45 (1), p. 23-28, ISSN 0003-9438, Leibniz Institute for Farm Animal Biology, Dummerstorf, Germany

Wilson , L.L., Egan, C.L., Terosky, T.L. 1997. Body measurements and body weights of special-fed Holstein Veal Calves. Journal of Dairy Science 80 (11): p. 3077-3082.ISSN 0022-0302, The American Dairy Science Association, USA 